\title{
OPEN The effects of repeated inhaler device handling education in COPD patients: a prospective cohort study
}

June Hong Ahn ${ }^{凶}$, Jin Hong Chung, Kyeong-Cheol Shin, Hyun Jung Jin, Jong Geol Jang, Mi Suk Lee \& Kwan Ho Lee

Inhaler education for chronic obstructive pulmonary disease (COPD) patients improves inhaler technique and adherence. However, the effects of such education on the quality of life and inhaler satisfaction remain unclear. Here, we evaluated inhaler handling and adherence, and changes in quality of life and inhaler satisfaction, after repeated education for COPD patients. We prospectively enrolled COPD patients who had used inhalers for over 1 month and evaluated the effects of repeated education. Three visits were made over 6 months; an advanced practice nurse evaluated inhaler technique and adherence, and instructed the patients in inhaler technique during face-toface sessions. Inhaler technique and adherence were assessed at every visits, and the modified Medical Research Council (mMRC) test, COPD Assessment Test (CAT), EuroQol-5D (EQ-5D), Patient Health Questionnaire (PHO-9), and Feeling of Satisfaction with Inhaler questionnaire (FSI-10) were administered before (visit 1) and after two educational sessions (visit 3). A total of 261 COPD patients (308 inhalers) were included. Education significantly reduced the proportion of critical errors after two educational sessions (visit 3$)$, from 43.2 to $8.8 \%(p<0.001)$. The proportion of highly compliant patients increased after two visits, from $81.6 \%$ to $87.7 \%(p=0.005)$. The FSI-10 score improved significantly after education, from $44.36 \pm 4.69$ to $47.64 \pm 4.08(p<0.001)$; the scores on the other instruments (mMRC, CAT, EQ-5D, and PHQ-9) did not improve. Repeated face-to-face inhaler education by an advanced practice nurse significantly improved inhaler satisfaction, technique, and adherence. However, inhaler education did not significantly improve quality of life.

Chronic obstructive pulmonary disease (COPD) exhibits many different phenotypes, and the prevalence ranged from 12.9 to $17.2 \%$ in the Korean National Health and Nutritional Examination Survey II (KNHANES II) ${ }^{1,2}$. Correct inhaler use is important: incorrect use is associated with an increased risk of acute exacerbation, hospital admission, emergency room visits, and a need for antimicrobials and oral steroids ${ }^{3-5}$. However, in the real world, inhaler mishandling and poor adherence are very common, despite the fact that most COPD patients receive education on inhaler use ${ }^{3,5,6}$. Many studies have shown that education reduces inhaler mishandling, significantly improving inhaler technique ${ }^{6-9}$.

Quality of life refers to satisfaction or happiness in aspects of life when an individual is affected by their health ${ }^{10,11}$. Quality of life of COPD patients was lower than that of the general population. High severity of COPD, depression, and osteoporosis were associated with lower quality of life in Korean COPD patients ${ }^{11}$. Patient satisfaction with inhaler device is associated with patient adherence and clinical outcomes. In a large, multinational, cross-sectional, real-world survey with COPD patients, significant association was reported between inhaler satisfaction and treatment adherence. Furthermore, there was a direct association between inhaler satisfaction and fewer COPD exacerbations ${ }^{12}$.

Few studies have examined the association between inhaler education and quality of life ${ }^{6,13-15}$; no study has explored the relationship between inhaler education and inhaler satisfaction. Thus, we evaluated inhaler handling and adherence, and changes in quality of life and inhaler satisfaction, after repeated education for COPD patients.

Division of Pulmonology and Allergy, Department of Internal Medicine, Yeungnam University Medical Center, College of Medicine, Yeungnam University, 170 Hyeonchung-ro, Namgu 42415, Daegu, Republic of Korea. ${ }^{\varpi}$ email: fireajh@ gmail.com; ghlee@med.yu.ac.kr 


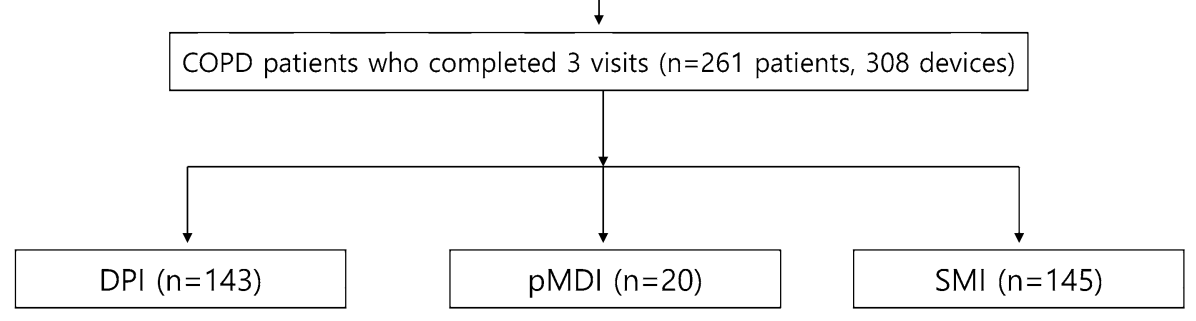

Figure 1. Flow diagram of the study subjects. COPD chronic obstructive pulmonary disease, DPI dry powder inhaler, $p M D I$ pressurized metered-dose inhaler, SMI soft mist inhaler.

\begin{abstract}
Materials and methods
Study design and subjects. This prospective study was conducted in the pulmonology outpatient department of the Regional Center for Respiratory Diseases, Yeungnam University Hospital (a tertiary university hospital in Daegu, South Korea) from January 2018 to May 2019. Patients aged over 40 years and diagnosed with COPD were initially enrolled, and all those who had used inhalers of any kind for more than 1 month were recruited to the study. The intervention included three visits over 6 months; follow-up visits were performed every 3 months. In total, 72 patients were excluded for the following reasons: inhaler device changed during the study period $(\mathrm{n}=30)$; lost to follow-up $(\mathrm{n}=40)$; and did not complete the three visits $(\mathrm{n}=2)$. COPD patients who completed 3 visits and maintained the same inhaler device during study period were finally analyzed. Finally, 261 patients using 308 inhalers were included (Fig. 1). The inhalers included the Turbuhaler, Breezhaler, Ellipta, Diskus, Genuair, Respimat, and pressurized metered dose inhalers (pMDI) models. We excluded patients using a pMDI with a spacer, using other inhalers, those with advanced cancer, and pregnant females.
\end{abstract}

Patient visits. During the study, patients who agreed to the study were enrolled among all COPD patients who visited our respiratory outpatient clinic. The intervention included three visits over 6 months; follow-up visits were performed every 3 months. All patients had undergone pulmonary function tests within the 3 months prior to enrolment. At visit 1 (baseline), written informed consent was obtained from all patients. A general questionnaire exploring age, sex, body mass index, smoking status, COPD duration, previous inhaler education, previous COPD education, and educational level was administered. The modified Medical Research Council test $(\mathrm{mMRC})^{16}$, the COPD Assessment Test $(\mathrm{CAT})^{17}$, the Mini-Mental State Examination (MMSE) $)^{18}$, the EuroQol5D (EQ-5D) instrument ${ }^{19}$, the Patient Health Questionnaire (PHQ-9) ${ }^{20}$, to assess the quality of life and the Feeling of Satisfaction with Inhaler questionnaire (FSI-10) ${ }^{21,22}$ were administered at the first visit. All questionnaires were available free online. An advanced practice nurse assessed inhaler technique and adherence, and delivered face-to-face training using the "teach-back" technique, in which the nurse says: "Can you show me what I showed you and explain it to me?" "Teach-back" is a technique that requires patients to explain or demonstrate their skills back after training ${ }^{23}$. Repetitive training using the "teach-back" technique was conducted in visit 1 until the patient fully understands the inhaler device and fully explain the operation of the inhaler. At visits 2 and 3 , the nurse re-assessed inhaler technique and adherence and delivered face-to-face training using "teachback" technique if any error was apparent. At visit 3, we re-administered the mMRC, CAT, EQ-5D, and PHQ-9, to assess changes in quality of life, and the FSI-10.

Data collection and definitions. An advanced practice nurse specializing in inhaler education performed all of the interviews and training sessions. The nurse was educated by our COPD specialists and had trained COPD patients in inhaler techniques for 3 years. Critical errors were defined as errors seriously compromising drug delivery to the lung. We created a standardized checklist of inhaler use critical steps by reference to the review literature ${ }^{24}$. The critical errors are listed in Table 2. Adherence was self-reported and graded as good, partial, or poor, according to whether the entire daily dose was taken, the daily dose (frequency or amount) taken was more or less than required, and the medication was taken only as needed or not at all, respectively ${ }^{25}$. The FSI-10 (10 questions) is a validated self-administered questionnaire evaluating patient satisfaction with their inhaler ${ }^{21,22}$. The answer options range from "hardly at all" (score of 1 on a 5-point Likert scale) to 5 "very" (score of 5); the total score thus ranges from 10 to 50; higher scores indicate better satisfaction. Inhaler convenience, maintenance, portability, and "feel" are all assessed by the FSI-10.

Statistical analysis. Continuous variables are expressed as means \pm standard deviations (SDs) and were compared using Student's $t$-test or the Mann-Whitney U test. Categorical variables were compared using the 


\begin{tabular}{|c|c|}
\hline Variable & $\mathrm{N}=261$ \\
\hline Age (years) & $69.8 \pm 7.7$ \\
\hline Male, n (\%) & $244(93.5)$ \\
\hline Body mass index $\left(\mathrm{kg} / \mathrm{m}^{2}\right)$ & $23.5 \pm 3.5$ \\
\hline \multicolumn{2}{|l|}{ Smoking status } \\
\hline Never-smoker & $35(13.4)$ \\
\hline Ex-smoker & $179(68.6)$ \\
\hline Current smoker & $47(18.0)$ \\
\hline COPD duration (years) & $3.6 \pm 4.3$ \\
\hline Multiple inhaler devices ( $\geq 2$ devices) & $47(18.0)$ \\
\hline Previous education on COPD & $249(95.4)$ \\
\hline Previous education on how to handle an inhaler & $249(95.4)$ \\
\hline \multicolumn{2}{|l|}{ Educational level } \\
\hline $\begin{array}{l}\text { Low ( } \leq 6 \text { years }) \\
\text { Higher ( }>6 \text { years) }\end{array}$ & \begin{tabular}{|l|}
$99(37.9)$ \\
$162(62.1)$ \\
\end{tabular} \\
\hline $\mathrm{FEV}_{1} / \mathrm{FVC}(\%)$ & $58.6 \pm 13.7$ \\
\hline Percentage predicted $\mathrm{FEV}_{1}$ & $63.5 \pm 17.5$ \\
\hline Percentage predicted DLCO $(\mathrm{n}=258)$ & $68.4 \pm 19.5$ \\
\hline \multicolumn{2}{|l|}{ GOLD stage } \\
\hline I, II & $204(78.1)$ \\
\hline III, IV & $57(21.9)$ \\
\hline mMRC score & $1.3 \pm 0.9$ \\
\hline CAT score & $9.9 \pm 5.6$ \\
\hline MMSE score $(\mathrm{n}=258)$ & $29.3 \pm 1.6$ \\
\hline Frequent exacerbations in the prior year & $65(24.9)$ \\
\hline
\end{tabular}

Table 1. Baseline characteristics of the COPD patients. Data are presented as means \pm standard deviations (ranges) or numbers (percentages). CATCOPD assessment test, COPD chronic obstructive pulmonary disease, $D L C O$ diffusion capacity for carbon monoxide, $F E V_{1}$ forced expiratory volume in $1 \mathrm{~s}, F V C$ forced vital capacity, GOLD Global Initiative for Chronic Obstructive Lung Disease, $m M R C$ modified Medical Research Council, MMSE Mini-Mental State Examination.

chi-squared test or Fisher's exact test. In all analyses, a two-tailed p-value $<0.05$ was considered to indicate statistical significance. All statistical analyses were performed using SPSS software (ver. 24.0; SPSS Inc., Chicago, IL, USA). A prospective power calculation indicated that an overall sample size of 220 was required to evaluate the efficacy of education ( $95 \%$ power, $\alpha=0.05$, effect size $=0.3$ ). To allow for dropout, we sought to enroll 260 patients $^{26}$.

Ethics approval and consent to participate. This study was conducted in accordance with all relevant tenets of the Declaration of Helsinki. The protocol was reviewed and approved by the institutional review board of our hospital (Yeungnam University Hospital Institutional Review Board 2017-09-012-001). Written informed consent was obtained from all patients.

\section{Results}

Baseline characteristics. Patient baseline characteristics are listed in Table 1 . The mean age was 69.8 years and males predominated (93.5\%). The mean body mass index was $23.5 \mathrm{~kg} / \mathrm{m}^{2}$ and the mean COPD duration was 3.6 years. In total, $47(18.0 \%)$ patients were current smokers and 179 (68.6\%) were ex-smokers; $95.4 \%$ had received previous education on COPD and inhaler handling. One-third of the patients were poorly educated. Most exhibited mild-to-moderate airflow limitation $(63.5 \pm 17.5 \%$ of the predicted forced expiratory volume in $\left.1 \mathrm{~s}\left[\mathrm{FEV}_{1}\right]\right)$. The mean $\mathrm{mMRC}$ and CAT scores were $1.3 \pm 0.9$ and $9.9 \pm 5.6$ respectively. The mean MMSE score was $29.3 \pm 1.6$.

Inhaler use/adherence before and after education. A total of 261 COPD patients using 308 inhaler devices were enrolled. The percentages of patients exhibiting at least one critical error during inhaler use, before and after education, are listed in Fig. 2. At visit 1,43.2\% (133/308) showed at least one critical error. After two educational visits, these values fell to $8.8 \%$ (27/308); education improved the use of all included inhalers (Table 2). All critical errors were reduced after repeated education. In terms of adherence, the proportion of good compliers increased after two educational sessions, from 81.6 to $87.7 \%$ ( $p=0.005$; Fig. 3). 
Any critical errors

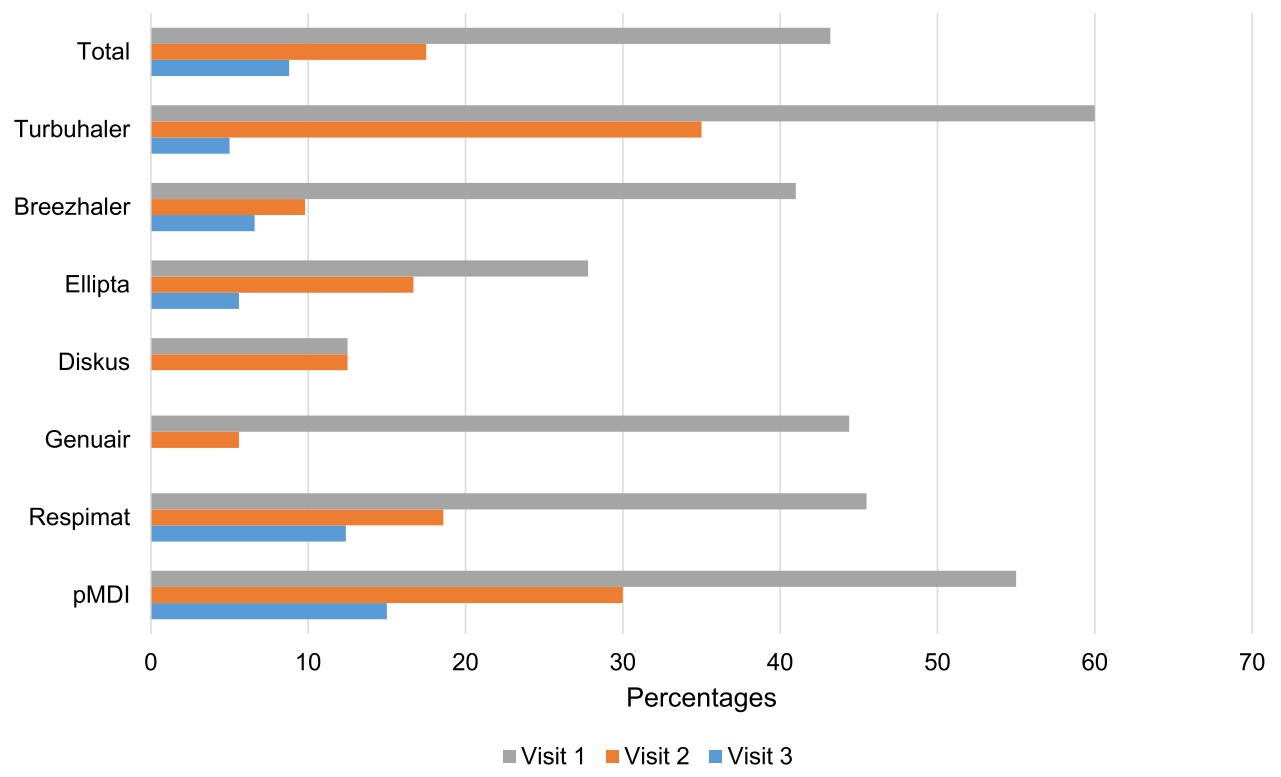

Figure 2. Inhaler use critical errors before and after education.

Quality of life before and after education. We compared the quality of life before (visit 1) and after (visit 3) education. The scores on the mMRC, CAT, EQ-5D, or PHQ-9 did not improve significantly (Table 3). Each parameters in the EQ-5D domain did not show any significant improvement after education (Table 4).

Inhaler satisfaction. Table 5 shows the inhaler satisfaction scores before and after education. Scores on all 10 items of the FSI- 10 (all 10 items $p<0.001$ respectively), and the overall score ( $44.36 \pm 4.69$ to $47.64 \pm 4.08$, $\mathrm{p}<0.001)$, improved significantly after two educational sessions.

\section{Discussion}

Of 261 COPD patients using 308 inhalers, at least one critical error during 133 (43.2\%) uses at visit 1. After two "teach-back" educational sessions, those values changed 27 (8.8\%), irrespective of inhaler type. The proportion of patients exhibiting good adherence also increased, as did inhaler satisfaction, but not the quality of life.

So far, studies on the effects of inhaler education on quality of life is controversial. While some studies reported positive associations between inhaler educational interventions and quality of life ${ }^{13,15,27-30}$, others did not $^{6,14}$. Two studies showing positive associations evaluated the short-term (1-3 months) effects of education ${ }^{13,27}$; the other two studies enrolled only asthma patients ${ }^{29,30}$. In our study, the mMRC, CAT, EQ-5D, or PHQ-9 instruments revealed no relationship between education and improved quality of life. The characteristics of our population (COPD patients only), and the relatively long interval before measurement of outcomes (6 months) may explain the lack of an association between education and improved quality of life. Although certain subgroups of patients may be expected to enjoy a better quality of life after inhaler education, more research is needed to confirm this.

Satisfaction with inhaler is defined as how satisfied patients' are with their inhaler devices regarding ease and convenient to use. Inhaler satisfaction is very important part of the treatment with chronic airway diseases, enhancing both adherence and disease control ${ }^{12,31}$. Inhaler satisfaction differs between different inhaler devices in asthma and COPD patients ${ }^{21,22}$. Previous study showed that patients with asthma were significantly more satisfied with the inhaler than patients with COPD. Younger age, good disease control, previous inhaler training, and good adherence were associated with high inhaler satisfaction level $\mathrm{s}^{32}$. We found that repeated education significantly improved satisfaction (on all 10 FSI-10 items) in COPD patients. Inhaler satisfaction improvement can affect various clinical outcomes in the long run. However, not much is known about the relationship between inhaler satisfaction improvement and clinical outcomes. Our study has proven the relationship between inhaler education and inhaler satisfaction, and future studies whether there is a correlation between an improved FSI-10 score and better disease control are imperative.

The GOLD 2019 guidelines state that, after reviewing the symptoms and determining the dyspnea and exacerbation status, inhaler technique/adherence should be repeatedly assessed; drug potency is irrelevant if the drug is not delivered properly ${ }^{33}$. Many studies found that educational interventions attenuated inhaler errors and improved adherence in patients with airway diseases ${ }^{6,7,13,24,27,34}$. Repeated education was the optimal approach. Most studies were performed in asthma patients ${ }^{7,35,36}$. Some studies enrolled COPD patients ${ }^{8,37,38}$, but most of the educational programs were brief. In three programs, three educational visits were scheduled at 2 -week intervals, or according to a 1-month program ${ }^{27,37,38}$. One study assessed changes in inhaler technique at 4-6 weeks after 


\begin{tabular}{|c|c|c|c|}
\hline \multirow[b]{2}{*}{ Critical steps of inhalation technique } & \multicolumn{2}{|l|}{ Any critical errors } & \multirow[b]{2}{*}{ P-value } \\
\hline & Before education (Visit 1) & After education (Visit 3) & \\
\hline \multicolumn{4}{|l|}{ Turbuhaler, $\mathbf{n}=\mathbf{2 0}$} \\
\hline Open the device correctly & $0(0)$ & $0(0)$ & \\
\hline Prime with device upright & $9(45.0)$ & $1(5.0)$ & 0.003 \\
\hline Seal lips around mouthpiece during inhalation & $0(0)$ & $0(0)$ & \\
\hline Inhale forcefully or deeply & $4(20.0)$ & $0(0)$ & 0.106 \\
\hline \multicolumn{4}{|l|}{ Breezhaler, $n=61$} \\
\hline Open the device correctly & $0(0)$ & $0(0)$ & \\
\hline Place capsule in the chamber & $1(1.6)$ & $0(0)$ & 1.000 \\
\hline Close the mouthpiece & $5(2.5)$ & $0(0)$ & 0.057 \\
\hline Press button to pierce the capsule & $13(21.3)$ & $0(0)$ & $<0.001$ \\
\hline Seal lips around mouthpiece during inhalation & $0(0)$ & $0(0)$ & \\
\hline Inhale forcefully or deeply & $16(26.2)$ & $4(6.6)$ & 0.003 \\
\hline Remove capsule and check for powder residue & $6(9.8)$ & $0(0)$ & 0.027 \\
\hline \multicolumn{4}{|l|}{ Ellipta, $n=36$} \\
\hline Open the device correctly & $2(5.6)$ & $1(2.8)$ & 1.000 \\
\hline Seal lips around mouthpiece during inhalation & $0(0)$ & $0(0)$ & \\
\hline Inhale forcefully or deeply & $8(22.2)$ & $1(2.8)$ & 0.028 \\
\hline \multicolumn{4}{|l|}{ Diskus, $n=8$} \\
\hline Open the device correctly & $0(0)$ & $0(0)$ & \\
\hline Pull the lever fully back & $1(12.5)$ & $0(0)$ & 1.000 \\
\hline Seal lips around mouthpiece during inhalation & $0(0)$ & $0(0)$ & \\
\hline Inhale forcefully or deeply & $0(0)$ & $0(0)$ & \\
\hline \multicolumn{4}{|l|}{ Genuair, $n=18$} \\
\hline Open the device correctly & $0(0)$ & $0(0)$ & \\
\hline $\begin{array}{l}\text { Hold the inhaler horizontally (green button facing upwards) for } \\
\text { priming }\end{array}$ & $3(16.7)$ & $0(0)$ & 0.229 \\
\hline Seal lips around mouthpiece during inhalation & $0(0)$ & $0(0)$ & \\
\hline Inhale forcefully or deeply & $6(33.3)$ & $0(0)$ & 0.019 \\
\hline \multicolumn{4}{|l|}{ Respimat, $n=145$} \\
\hline Twist the base one half-turn & $28(19.3)$ & $4(2.8)$ & $<0.001$ \\
\hline Open the device correctly & 27 (18.6) & $4(2.8)$ & $<0.001$ \\
\hline Seal lips around mouthpiece during inhalation & $10(6.9)$ & $2(1.4)$ & 0.035 \\
\hline Synchronize actuation and inhalation & $36(24.8)$ & $12(8.3)$ & $<0.001$ \\
\hline Inhale slowly and deeply & $39(26.9)$ & $13(9.0)$ & $<0.001$ \\
\hline \multicolumn{4}{|l|}{ pMDI, $n=20$} \\
\hline Open the device correctly & $0(0)$ & $0(0)$ & \\
\hline Shake well (suspension formulations only) & $3(15.0)$ & $0(0)$ & 0.231 \\
\hline Keep inhaler upright & $3(15.0)$ & $1(5.0)$ & 0.605 \\
\hline Seal lips around mouthpiece during inhalation & $0(0)$ & $0(0)$ & \\
\hline Synchronize actuation and inhalation & $5(25.0)$ & $1(5.0)$ & 0.182 \\
\hline Inhale slowly and deeply & $6(30.0)$ & $2(10.0)$ & 0.235 \\
\hline
\end{tabular}

Table 2. Critical errors for each inhaler device before and after education. Data are presented as numbers (percentages).

education ${ }^{8}$. We scheduled three educational visits at 3-month intervals and analyzed the outcomes at 6 months. Our study is unique and has strength in that it included relatively long-term evaluations (6 months) after repeated education of COPD patients, and clearly shows the effectiveness of education on inhaler technique and adherence for a relatively long period ( 3 months) after one session of education.

Critical errors were common (all inhaler types) at visit 1. Among DPI users, Turbuhaler, Breezhaler, and Genuair users made more critical errors than Diskus and Ellipta users. After two educational sessions, the critical error rate was less than $10 \%$ among the DPI users. Those using the Respimat and pMDIs made more critical errors than the DPI users at visit 1 . Education decreased the initial rate of critical errors of the Respimat and pMDI users to $10 \%$. Although the improvements differed somewhat among the devices, all critical error rates fell.

One large real-world study assessed 2935 COPD patients using 3393 devices; critical errors were divided into dose preparation and delivery errors ${ }^{3}$. Dose preparation errors were common in Respimat and Turbuhaler users, and dose delivery errors in Respimat and pMDI users; our findings were similar. Dose preparation errors 


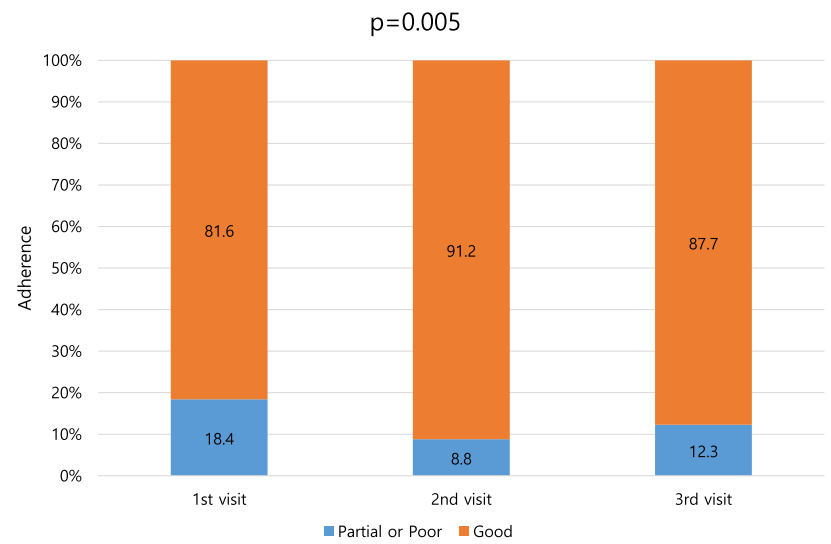

Figure 3. Adherence before and after education.

\begin{tabular}{|l|l|l|l|}
\hline & Before education $(\mathbf{n}=\mathbf{2 6 1})$ & After education $(\mathbf{n}=\mathbf{2 6 1})$ & P-value \\
\hline mMRC & $1.31 \pm 0.87$ & $1.27 \pm 0.96$ & 0.617 \\
\hline CAT & $9.92 \pm 5.56$ & $10.78 \pm 6.44$ & 0.102 \\
\hline EQ-5D & $0.86 \pm 0.11$ & $0.85 \pm 0.14$ & 0.292 \\
\hline PHQ-9 & $1.14 \pm 2.30$ & $1.56 \pm 3.16$ & 0.101 \\
\hline
\end{tabular}

Table 3. Quality of life before and after education. Data are presented as means \pm standard deviations (ranges). CATCOPD assessment test, EQ-5D EuroQol-5D, FSI-10 Feeling of Satisfaction with Inhaler questionnaire, mMRC modified Medical Research Council, PHQ-9Patient Health Questionnaire.

\begin{tabular}{|c|c|c|c|c|c|}
\hline \multirow[b]{2}{*}{ EQ-5D domains } & \multirow[b]{2}{*}{ Education status } & \multicolumn{3}{|l|}{ EQ-5D level } & \multirow[b]{2}{*}{ P value } \\
\hline & & No problem & Some problem & Severe problem & \\
\hline \multirow{2}{*}{ Mobility } & Before education & $161(61.7)$ & $98(37.5)$ & $2(0.8)$ & \multirow{2}{*}{0.791} \\
\hline & After education & $165(63.2)$ & $92(35.2)$ & $4(1.5)$ & \\
\hline \multirow{2}{*}{ Self-care } & Before education & $216(82.8)$ & 44 (16.9) & $1(0.4)$ & \multirow{2}{*}{0.606} \\
\hline & After education & $222(85.1)$ & $35(13.4)$ & $4(1.5)$ & \\
\hline \multirow{2}{*}{ Usual activities } & Before education & $193(73.9)$ & $67(25.7)$ & $1(0.4)$ & \multirow{2}{*}{0.002} \\
\hline & After education & $160(61.3)$ & $98(37.5)$ & $3(1.1)$ & \\
\hline \multirow{2}{*}{ Pain/discomfort } & Before education & $194(74.3)$ & $65(24.9)$ & $2(0.8)$ & \multirow{2}{*}{0.272} \\
\hline & After education & $183(70.1)$ & $75(28.7)$ & $3(1.1)$ & \\
\hline \multirow{2}{*}{ Anxiety/depression } & Before education & $195(74.7)$ & $63(24.1)$ & $3(1.1)$ & \multirow{2}{*}{0.846} \\
\hline & After education & $193(73.9)$ & $65(24.9)$ & $3(1.1)$ & \\
\hline
\end{tabular}

Table 4. EQ-5D domains before and after education. Data are presented as numbers (percentages). EQ5DEuroQol-5D.

were commonly observed in Turbuhaler users (failure to prime with the device upright, $45.0 \%$ ), Breezhaler users (failure to press the button that pierces the capsule, 21.3\%), Genuair users (failure to hold the inhaler horizontally for priming, 16.7\%) and Respimat users (failure to twist the base by one half-turn, 19.3\%). Dose delivery errors were more common in Respimat and pMDI users, and included failure to synchronize actuation and inhalation ( $24.8 \%$ and $25.0 \%$, respectively) and failure to inhale slowly and deeply ( 26.9 and $30.0 \%$, respectively). All critical error rates fell after two educational interventions.

Our work had certain limitations. First, this was a single-center study lacking a control group, so selection bias was inevitable. Inhaler use assessment and education are essential components of COPD management. so it would have been unethical to include a control group. Therefore, we compared several parameters before and after the educational intervention. Also, 40 patients were lost to follow-up, such that the utility of the education may have been overemphasized because the lost patients might have rejected the intervention. However, the marked improvements in inhaler handling, adherence, and satisfaction that we observed emphasize that education is useful. Second, other factors known to affect quality of life in COPD, such as the type of inhaler and the comorbidities, were not included in this study, Finally, we did not explore how long the effects of education persisted; more studies are needed on this topic. 


\begin{tabular}{|c|c|c|c|}
\hline & Before education $(n=261)$ & After education $(n=261)$ & P-value \\
\hline FSI-10 & $44.36 \pm 4.69$ & $47.64 \pm 4.08$ & $<0.001$ \\
\hline Easy to learn how to use the inhaler & $4.36 \pm 0.70$ & $4.80 \pm 0.55$ & $<0.001$ \\
\hline Easy to prepare the inhaler for use & $4.48 \pm 0.58$ & $4.80 \pm 0.52$ & $<0.001$ \\
\hline Easy to use the inhaler & $4.51 \pm 0.67$ & $4.77 \pm 0.55$ & $<0.001$ \\
\hline Easy to keep the inhaler clean and in good working condition & $4.50 \pm 0.60$ & $4.85 \pm 0.39$ & $<0.001$ \\
\hline Easy to continue normal activities with the use of the inhaler & $4.38 \pm 0.68$ & $4.69 \pm 0.65$ & $<0.001$ \\
\hline Inhaler fits my lips comfortably & $4.51 \pm 0.66$ & $4.84 \pm 0.46$ & $<0.001$ \\
\hline Easy to use in terms of size and weight & $4.65 \pm 0.49$ & $4.87 \pm 0.40$ & $<0.001$ \\
\hline Easy to carry the inhaler & $4.20 \pm 0.74$ & $4.49 \pm 0.67$ & $<0.001$ \\
\hline I feel that I am using the inhaler correctly & $4.45 \pm 0.77$ & $4.78 \pm 0.57$ & $<0.001$ \\
\hline Overall, I am satisfied with the inhaler & $4.33 \pm 0.73$ & $4.75 \pm 0.60$ & $<0.001$ \\
\hline
\end{tabular}

Table 5. Inhaler satisfaction before and after education. Data are presented as means \pm standard deviations (ranges). FSI-10 Feeling of Satisfaction with Inhaler questionnaire.

This study also had several strengths. First, few such studies have been performed in Korea ${ }^{27,37}$; also, we enrolled only COPD patients; COPD and asthma differ, so the effects of education may also differ between these populations. Second, we assessed many quality of life outcomes (using the mMRC, CAT, EQ-5D, and PHQ-9 instruments), as well as inhaler satisfaction (using the FSI-10), and inhaler technique and adherence. As mentioned above, few studies have explored changes in quality of life after educational interventions. And to the best of our knowledge, this is the first study to report improved inhaler satisfaction after education. Improvements in inhaler satisfaction can lead to improvements in various clinical outcomes in COPD patients over the long time. This study highlights once again the importance of repeated inhaler education. Third, our study is different from other studies in that we have assessed the effects over a relatively long period of time (6 months). An assessment of how long the effects of education last can give the answer to how often education should be implemented. Our research is unique in this respect. Fourth, we found that the inhaler usage training was highly effective to improve inhaler satisfaction, technique, and adherence in a real-world setting, and that the effects were relatively persistent. In future studies, we will seek to precisely determine how long the effects of education persist.

\section{Conclusion}

Repeated education delivered by an advanced practice nurse improved inhaler satisfaction, technique, and adherence. However, inhaler education did not significantly improve quality of life. More detailed studies are needed to determine the number of educational sessions required, the optimal intervals, and the duration of any benefits thus achieved.

Received: 2 June 2020; Accepted: 2 November 2020

Published online: 12 November 2020

\section{References}

1. Yoo, K. H. et al. Prevalence of chronic obstructive pulmonary disease in Korea: The fourth Korean National Health and Nutrition Examination Survey, 2008. Respirology 16, 659-665. https://doi.org/10.1111/j.1440-1843.2011.01951.x (2011).

2. Hwang, Y. I., Park, Y. B. \& Yoo, K. H. Recent trends in the prevalence of chronic obstructive pulmonary disease in Korea. Tuberc. Respir. Dis. 80, 226-229. https://doi.org/10.4046/trd.2017.80.3.226 (2017).

3. Molimard, M. et al. Chronic obstructive pulmonary disease exacerbation and inhaler device handling: real-life assessment of 2935 patients. Eur. Respir. J. 49, https://doi.org/10.1183/13993003.01794-2016 (2017).

4. Melani, A. S. et al. Inhaler mishandling remains common in real life and is associated with reduced disease control. Respir. Med. 105, 930-938. https://doi.org/10.1016/j.rmed.2011.01.005 (2011).

5. Ahn, J. H. et al. Critical inhaler handling error is an independent risk factor for frequent exacerbations of chronic obstructive pulmonary disease: Interim results of a single center prospective study. Int. J. Chronic Obstruct. Pulm. Dis. 14, 2767-2775. https ://doi.org/10.2147/COPD.S234774 (2019).

6. Pothirat, C. et al. Evaluating inhaler use technique in COPD patients. Int. J. Chronic Obstruct. Pulm. Dis. 10, 1291-1298. https:// doi.org/10.2147/COPD.S85681 (2015).

7. Crane, M. A., Jenkins, C. R., Goeman, D. P. \& Douglass, J. A. Inhaler device technique can be improved in older adults through tailored education: Findings from a randomised controlled trial. NPJ Primary Care Respir. Med. 24, 14034. https://doi.org/10.1038/ npjpcrm.2014.34 (2014).

8. Bouwmeester, C., Kraft, J. \& Bungay, K. M. Optimizing inhaler use by pharmacist-provided education to community-dwelling elderly. Respir. Med. 109, 1363-1368. https://doi.org/10.1016/j.rmed.2015.07.013 (2015).

9. Harnett, C. M. et al. A study to assess inhaler technique and its potential impact on asthma control in patients attending an asthma clinic. J. Asthma 51, 440-445. https://doi.org/10.3109/02770903.2013.876650 (2014).

10. Ware, J. E., Jr. \& Sherbourne, C. D. The MOS 36-item short-form health survey (SF-36). I. Conceptual framework and item selection. Med. Care 30, 473-483 (1992).

11. Kwon, H. Y. \& Kim, E. Factors contributing to quality of life in COPD patients in South Korea. Int. J. Chronic Obstruct. Pulm. Dis. 11, 103-109. https://doi.org/10.2147/COPD.S90566 (2016).

12. Chrystyn, H. et al. Impact of patients' satisfaction with their inhalers on treatment compliance and health status in COPD. Respir. Med. 108, 358-365. https://doi.org/10.1016/j.rmed.2013.09.021 (2014).

13. Goris, S., Tasci, S. \& Elmali, F. The effects of training on inhaler technique and quality of life in patients with COPD. J. Aerosol Med. Pulm. Drug Deliv 26, 336-344. https://doi.org/10.1089/jamp.2012.1017 (2013). 
14. Hesselink, A. E. et al. Effectiveness of an education programme by a general practice assistant for asthma and COPD patients: Results from a randomised controlled trial. Patient Educ. Couns. 55, 121-128. https://doi.org/10.1016/j.pec.2003.08.007 (2004).

15. Jang, J. G. et al. Comprehensive effects of organized education for patients with chronic obstructive pulmonary disease. Int. J. Chronic Obstruct. Pulm. Dis. 14, 2603-2609. https://doi.org/10.2147/COPD.S221673 (2019).

16. Bestall, J. C. et al. Usefulness of the Medical Research Council (MRC) dyspnoea scale as a measure of disability in patients with chronic obstructive pulmonary disease. Thorax 54, 581-586. https://doi.org/10.1136/thx.54.7.581 (1999).

17. Jones, P. W. et al. Development and first validation of the COPD assessment test. Eur. Respir. J. 34, 648-654. https://doi. org/10.1183/09031936.00102509 (2009).

18. Folstein, M. F., Folstein, S. E. \& McHugh, P. R. "Mini-mental state". A practical method for grading the cognitive state of patients for the clinician. J. Psychiatric Res. 12, 189-198, https://doi.org/10.1016/0022-3956(75)90026-6 (1975).

19. EuroQol-A new facility for the measurement of health-related quality of life. Health Policy 16, 199-208, https://doi. org/10.1016/0168-8510(90)90421-9 (1990).

20. Spitzer, R. L., Kroenke, K. \& Williams, J. B. Validation and utility of a self-report version of PRIME-MD: The PHQ primary care study. Primary Care Evaluation of Mental Disorders. Patient Health Questionnaire. Jama 282, 1737-1744, https://doi.org/10.1001/ jama.282.18.1737 (1999).

21. Zervas, E., Samitas, K. \& Gaga, M. Assessment of satisfaction with different dry powder inhalation devices in Greek patients with COPD and asthma: The ANASA study. Int. J. Chronic Obstruct. Pulm. Dis. 11, 1845-1855. https://doi.org/10.2147/COPD.S1138 70 (2016).

22. Perpina Tordera, M. et al. Assessment of patient satisfaction and preferences with inhalers in asthma with the FSI-10 Questionnaire. Arch. Bronconeumol. 44, 346-352 (2008).

23. Dantic, D. E. A critical review of the effectiveness of 'teach-back'technique in teaching COPD patients self-management using respiratory inhalers. Health Educ. J. 73, 41-50 (2014).

24. Usmani, O. S. et al. Critical inhaler errors in asthma and COPD: A systematic review of impact on health outcomes. Respir. Res. 19, 10. https://doi.org/10.1186/s12931-017-0710-y (2018).

25. Baddar, S., Jayakrishnan, B. \& Al-Rawas, O. A. Asthma control: Importance of compliance and inhaler technique assessments. J Asthma 51, 429-434. https://doi.org/10.3109/02770903.2013.871558 (2014).

26. Faul, F., Erdfelder, E., Buchner, A. \& Lang, A. G. Statistical power analyses using G*Power 3.1: Tests for correlation and regression analyses. Behav. Res. Methods 41, 1149-1160, 10.3758/BRM.41.4.1149 (2009).

27. Lee, J. Y. et al. Effects of educational interventions for chronic airway disease on primary care. J. Korean Med. Sci. 31, 1069-1074. https://doi.org/10.3346/jkms.2016.31.7.1069 (2016).

28. Basheti, I. A., Armour, C. L., Bosnic-Anticevich, S. Z. \& Reddel, H. K. Evaluation of a novel educational strategy, including inhaler-based reminder labels, to improve asthma inhaler technique. Patient Educ. Couns. 72, 26-33. https://doi.org/10.1016/j. pec.2008.01.014 (2008).

29. Plaza, V. et al. A repeated short educational intervention improves asthma control and quality of life. Eur. Respir. J. 46, 1298-1307. https://doi.org/10.1183/13993003.00458-2015 (2015).

30. Yildiz, F. Importance of inhaler device use status in the control of asthma in adults: The asthma inhaler treatment study. Respir. Care 59, 223-230. https://doi.org/10.4187/respcare.02478 (2014).

31. Plaza, V. et al. Impact of patient satisfaction with his or her inhaler on adherence and asthma control. Allergy Asthma Proc. 39, 437-444. https://doi.org/10.2500/aap.2018.39.4183 (2018).

32. Plaza, V. et al. Determinants and differences in satisfaction with the inhaler among patients with asthma or COPD. J. Allergy Clin. Immunol. Pract. 8, 645-653, https://doi.org/10.1016/j.jaip.2019.09.020 (2020).

33. Singh, D. et al. Global strategy for the diagnosis, management, and prevention of chronic obstructive lung disease: The GOLD science committee report 2019. Eur. Respir. J. 53, https://doi.org/10.1183/13993003.00164-2019 (2019).

34. Klijn, S. L. et al. Effectiveness and success factors of educational inhaler technique interventions in asthma \& COPD patients: A systematic review. NPJ Prim. Care Respir. Med. 27, 24. https://doi.org/10.1038/s41533-017-0022-1 (2017).

35. Bosnic-Anticevich, S. Z., Sinha, H., So, S. \& Reddel, H. K. Metered-dose inhaler technique: The effect of two educational interventions delivered in community pharmacy over time. J. Asthma 47, 251-256. https://doi.org/10.3109/02770900903580843 (2010).

36. Takemura, M. et al. Repeated instruction on inhalation technique improves adherence to the therapeutic regimen in asthma. J. Asthma 47, 202-208. https://doi.org/10.3109/02770900903581692 (2010).

37. Yoo, K. H. et al. Short-term evaluation of a comprehensive education program including inhaler training and disease management on chronic obstructive pulmonary disease. Tuberc. Respir. Dis. 80, 377-384. https://doi.org/10.4046/trd.2017.0041 (2017).

38. Kim, A. et al. Factors affecting satisfaction with education program for chronic airway disease in primary care settings. J. Thorac. Dis. 9, 1911-1918. https://doi.org/10.21037/jtd.2017.06.01 (2017).

\section{Acknowledgements}

We sincerely thank Mi Jeong Nam for her invaluable efforts with respect to the data collection.

\section{Author contributions}

Conception or design: J.H.A., K.H.L. Acquisition, analysis, or interpretation of data: J.H.A., J.H.C., K.C.S., H.J.J., J.G.J., M.S.L., K.H.L. Drafting the work or revising: J.H.A., K.H.L. Final approval of the manuscript: J.H.A., J.H.C., K.C.S., H.J.J., J.G.J., M.S.L., K.H.L.

\section{Funding}

The work was supported by the Yeungnam University Research Fund (2020).

\section{Competing interests}

The authors declare no competing interests.

\section{Additional information}

Correspondence and requests for materials should be addressed to J.H.A. or K.H.L.

Reprints and permissions information is available at www.nature.com/reprints.

Publisher's note Springer Nature remains neutral with regard to jurisdictional claims in published maps and institutional affiliations. 
(c) (i) Open Access This article is licensed under a Creative Commons Attribution 4.0 International cc) License, which permits use, sharing, adaptation, distribution and reproduction in any medium or format, as long as you give appropriate credit to the original author(s) and the source, provide a link to the Creative Commons licence, and indicate if changes were made. The images or other third party material in this article are included in the article's Creative Commons licence, unless indicated otherwise in a credit line to the material. If material is not included in the article's Creative Commons licence and your intended use is not permitted by statutory regulation or exceeds the permitted use, you will need to obtain permission directly from the copyright holder. To view a copy of this licence, visit http://creativecommons.org/licenses/by/4.0/.

(C) The Author(s) 2020 